\title{
The Capacity Building programmes of GITEWS - visions, goals, lessons learned, and re-iterated needs and demands
}

\author{
T. Schlurmann ${ }^{1,{ }^{*}}$ and M. Siebert ${ }^{2}$ \\ ${ }^{1}$ Franzius-Institute of Hydraulic, Waterways and Coastal Engineering, Leibniz University Hannover, Hannover, Germany \\ ${ }^{2}$ Deutsche Gesellschaft für Internationale Zusammenarbeit (GIZ) GmbH, Eschborn, Germany \\ * previously at: Institute for Environment and Human Security, United Nations University, UNU-EHS, UN Campus, \\ Herman-Ehlers-Str. 10, 53113 Bonn, Germany
}

Received: 1 October 2010 - Revised: 22 December 2010 - Accepted: 22 December 2010 - Published: 2 February 2011

\begin{abstract}
It was envisioned that the framework of the German-Indonesian Tsunami Early Warning System (GITEWS) should achieve an integral architecture and overarching technical design of an end-to-end tsunami early warning system (TEWS). In order to achieve this ambitious goal on a national and local level, a tailored set of capacity building measures has been started and implemented. The programme was meant and designed to meet requirements and urgent needs considering awareness raising campaigns, technical trainings and higher level education programs. These components have been integrated as complementary modules in order to ensure facilitating the early warning system to be operated, maintained and improved, and that institutions and people in coastal areas will respond adequately and timely in case of future tsunamis. Remarkable progress has been accomplished as well as programs and campaigns are being implemented in regard to a sustainable capacity development conducted by national institutions in Indonesia. Yet, local administrative and preparedness efforts on the Indonesian coastlines are still underdeveloped. This stems from the fact of missing links towards sustainable coastal zone management schemes on a broad local level. Yet, the demand and urgent need for an adequate and integrated disaster risk reduction and management addressing also other hazards in the region of interest is (still) substantial. Given the tragic loss of life and severe damages resulting from the December 2004 tsunami and recent series of severe earthquakes, the need for urgent mitigating action in the imperilled coastal regions of Sumatra
\end{abstract}

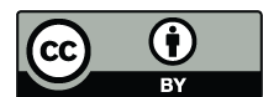

Correspondence to: T. Schlurmann (schlurmann@ fi.uni-hannover.de) and Java remains extremely high. The conceptual Capacity Building framework, its anticipated goals in the beginning of the project and, lately, the finally achieved objectives are promising. A significant contribution for mainstreaming scientific approaches and transfer methodological disaster risk reduction attempts towards other regions exposed to coastal hazards is still pending. Local authorities and researchers in tentative affected regions are now trained and enabled to disseminate and apply their knowledge and planning experience to other coastal regions in the area to help facilitating and multiplying effective disaster management plans and strategies. Yet, the Capacity Building framework within GITEWS also elucidated gaps in the early warning chain so that updated and to some extent reiterated needs and demands in Capacity Building programs in any future research or development cooperation project are presented and discussed.

\section{Background information}

Tsunamis are one of the largest and most devastating naturally created geophysical extreme hazards which put countless coastal stretches worldwide at risk. The great Sumatra-Andaman earthquake and succeeding tsunami of December 2004 caused disastrous property damage and loss of life. It underscored the importance of understanding and studying the inherent seismic and tsunami hazards of subduction zones. This disaster also underscored to progress the development of sensor networks and foster public policy to realize global end-to-end tsunami early warning systems (Bernard et al., 2006; Synolakis and

Published by Copernicus Publications on behalf of the European Geosciences Union. 
Bernard, 2006). Achieving these aspired goals require forging a chain linking basic science to people's everyday lives as Sieh (2006) clarifies. The intermediate links in this chain are emergency response preparedness, warning capability, education and infrastructural changes. In this regard Lauterjung et al. (2010) provide an unmistakable picture on the challenge of establishing a tsunami early warning system in the vicinity of the Sunda Arc in the Republic of Indonesia making an effort to address and integrate the links in this chain.

Following the catastrophic impacts of the 26 December 2004 tsunami, the Government of Germany, under initiative of the Federal Ministry for Education and Research (BMBF), launched the German Indonesian - Tsunami Early Warning System (GITEWS) project to contribute to the implementation of a tsunami warning system in Indonesia (Rudloff et al., 2009). Although it is widely known that the Sumatran megathrust has failed considerably in December 2004, March 2005 and September 2007, the segment along the northern Mentawai islands still is relatively intact, i.e. seismically locked. For that reason, various authors draw attention to the substantial tsunami hazard potential in the Indonesian densely-populated urban agglomeration, the city of Padang, with about 850000 inhabitants located on the western shore of Sumatra (Borrero et al., 2006; McCaffrey, 2007; McCloskey et al., 2007; Okal and Synolakis, 2008). So, it is widely acknowledged that the region of the Mentawai Islands and in adjacent areas proves a huge seismic moment deficit which has progressively accumulated since the last recorded major earthquakes in 1797 and 1833. In this regard, McCloskey et al. (2010) very recently point to that particular piece of evidence and accordingly demand adequate warning tools and sophisticated sensor systems as well as tailor-made Capacity Building measures in the particular region as the tsunami risk remains unabated and should be sturdily re-addressed by any ongoing initiative.

Depicting that framework and given the tragic loss of life and severe damages resulting from the September 2009 Padang earthquake which fortunately did not trigger a destructive tsunami, the need for urgent mitigating action in Padang remains extremely high. In reference to the September 2009 earthquake, Hoppe and Mahadiko (2010) remarkably report of the intensity of the event causing severe destruction and panic in Padang. An aftermath survey, conducted by GTZ-GITEWS together with KOGAMI (Tsunami Alert Community, a local NGO) and with support from the Last Mile Project as well as the local office of the National Disaster Management Agency (BPBD Badan Nasional Penanggulangan Bencana), showed that only about $50 \%$ of roughly 200 interviewees did evacuate. Although this sample is not fully representative in statistical terms, it gives clear sign of improper evacuation attitudes of untrained/unwilling individuals or misleading warning perceptions so that further drills and campaigns are to a great extent needed.

\section{Conceptional framework}

The core of the project focused on the conception, development and implementation of a series of sophisticated sensors and state-of-the-art early warning technologies. On the other hand, the strengthening of academic, technical and institutional capacities to monitor and forecast as well as to prepare and enhance awareness as well as capabilities of the society to arrange for future tsunamis. This complementary element was also considered as a vital part to finally achieve an end-to-end tsunami early warning system in order to be properly operated, maintained, improved and upgraded in future decades, and that the people in coastal areas will respond timely in case a warning is issued. During an extensive fact finding mission mid 2005, it was soundly agreed by the relevant programme partnering institutions on German and Indonesian sides that Capacity Building and ongoing research in the long-term are to a great extent required to assure the proper operation and sustainability of the proposed early warning system. Thus, the human and institutional dimension of the functioning and sustainability of the TEWS was given strong emphasis.

However, the initial lack of precise information or at least distinct and transparent overview on human resources needed to run the TEWS made it difficult from the beginning to outline a solid plan to complement existing human resources and information infrastructure. Although the partnering Indonesian research agencies declared numbers and levels of experts required to operate and maintain the system, it was yet not elucidated if these demands are fully appropriate for the new technology being developed and transferred. Likewise, clear evaluations and priorities on research fields to upgrade the TEWS in the future remained unabated. To this end, once the design of the system was initiated to progress, an additional task for the German research institutions was to outline distinctly every relevant issue on Capacity Building at all levels of academic, expert and social aspects so that a precise plan could be elaborated in close and constructive co-operation with the Indonesian partnering institutions. Finally, it worked out successfully.

\section{GITEWS - Capacity Building (CB)}

\subsection{Rationale}

The sustainable operation of the system depends not only on the establishment of the required technological bases such as earthquake detection, ocean instrumentation, modelling and earth observation data, but also on the development of the institutional and human capacities deemed necessary for the nationwide implementation and application of the system as well as structures for effective decision making in Indonesia. In addition to the implementation of its technical components, GITEWS consequently includes 
Capacity Building activities that target individuals, decisionmakers, administrative bodies, disaster risk management organizations as well as private sector at local and national levels.

\subsection{Objectives}

In general, the basic concept of Capacity Building (CB) signifies establishing resources needed to accomplish the mission or achieve goals to disseminate a realistic assessment of risks concerning extreme natural hazards with appropriate technical and socio-economic equipment. Thus, CB also incorporates training programmes which could be based upon strengthening the capabilities of individuals and institutions to focus on the occurrences and effects of natural hazard-related phenomena and processes as well as on their associated risks to prevent or mitigate disasters. Moreover, academic scholars should be integrated into relevant research projects in order to gain useful practical insights and the basic conceptions of project management through continuing education. Moreover, networking or collaborative research projects with institutes in developing countries are also envisaged to foster capacity development, learning and governance programs. In addition, governmental agencies and other national and international decision makers needing a range of scientific and engineering tools to effectively prevent or mitigate disasters are supported by experts and other competencies within the framework of the project by means of capacity development programmes as well as through co-operations and networking.

\subsection{Final design and implementation}

Based on these objectives, the GITEWS capacity building programme incorporates three dimensions being integrated in subprojects targeting the scientific audience and technological sphere as well as national institutions and local communities.

The work package Capacity Building within GITEWS has been structured into three main components accordingly, i.e.:

1. Academic and technical programmes: development and enhancement of research capabilities and technical skills of individuals by means of an arrangement of coordinated $\mathrm{PhD}$ and tailor-made PostDoc programmes and set of workshops and seminars to expand abilities and expertise of scientists and technicians in the relevant organizations and institutions in order to meet the scientific and technological needs of the GITEWS.

2. Institutional development programmes: development and strengthening of operational institutions and governmental bodies to help enabling cooperation, management and organizational structure of TEWS at national level.
3. Local disaster mitigation programmes: generate and progress warning and disaster preparedness mechanisms and strategies on local administrative and organisational level in three pilot areas, i.e. Padang, Western Sumatra; Cilacap, South-Java, and Kuta, Bali.

In this context the Deutsche Gesellschaft für Technische Zusammenarbeit (GTZ) GmbH (German Technical Corporation) and the Institute for Environment and Human Security, United Nations University (UNU), have been mandated to jointly steer and manage the Capacity Building work package on the German project side in collaboration with other institutions, i.e. Capacity Building International (InWEnt), the Federal Institute for Geosciences and Natural Resources (BGR), the German Research Centre for Geosciences (GFZ) as well as a subdivision of the German Aerospace Center (DLR). In accordance to an early Indonesian implementation plan in 2005, called the Grand Scenario, the Indonesian Institute of Science (LIPI) under guidance of the State Ministry of Research and Technology of the Republic of Indonesia (RISTEK) have been the major partnering bodies in charge of initiating and coordinating the Capacity Building components for the Indonesian research institutions in regard to the successful implementation of the GITEWS components within the full Indonesian tsunami early warning system, defined as InaTEWS.

During implementation it was essential to establish a so-called Capacity Building Unit (CBU) on the national level in Indonesia closely affiliated to the key institution RISTEK capable to monitor and assist all conducted Capacity Building efforts and initiated attempts on respected levels countrywide in order to detect gaps and advise institutions how to fill them, e.g. to coordinate technical trainings, courses or educational campaigns or to develop teaching and awareness materials in Indonesia on the whole. Such a CBU elaborated concepts for human resources development schemes, identified target groups for training measures, cleared classification of training needs and existing schemes, steered and developed training modules, training management and quality control, organized seminars for technical training and developed continuing education schemes in co-operation with Indonesian and German institutions. This CBU was anticipated to be composed of Indonesian staff supported initially by German experts and has been transformed later into a unique unit with a task to coordinate and administer educational efforts spanning all research agencies and institutions, levels, and donors focussing on Early Warning with merely Indonesian experts. The realization of the CBU and training measures contributed to the development of a structure which on its own is able to coordinate trainings and human resource development in the future. Next to building capacities, the implementation of the CBU advanced to a platform supporting the development, coordination and integration of activities of diverse InaTEWS stakeholders. 
In line with this tailored set of Capacity Building components addressing and strengthening individuals, the focus was moreover set to strengthen the institutional and human resource capacity in organizations and governmental bodies on the national level in order to build a sustainable, effective and self-reliant TEWS, also aimed to strengthen the capacities and capabilities of national and local decision making structures. The main tasks in this respect included in a first step to identify and assess the different stakeholders, their mandates and institutional capabilities in order to enable, in a second step, an institutional mapping approach and to facilitate a new network of stakeholders and define their interactions in decision making on policies and guideline.

In order to complement the above stated Capacity Building components, a third element on the generation and progressing of warning and disaster preparedness mechanisms and strategies on local administrative and organizational level in three pilot areas, i.e. Padang, Western Sumatra; Cilacap, South-Java, and Kuta, Bali, has been moved forward to a large extent. In Indonesia, the local level which is still in progress of the decentralization and democratization procedure plays an important role in the implementation of the tsunami early warning system. With an increasing autonomy of the regions, the municipalities (in Bahasa: Kabupaten) and cities (in Bahasa: Kota) obtain more and more competences and responsibilities, e.g. on disaster management and prevention. This stringent decentralization is on one hand supportive for a locally customized disaster management to encourage decision making and initiate execution of an early warning chain, but on the other hand, it is rather uncertain whether the local authorities and capacities as well established mitigation structures are existent and functioning for an effective, institutionalized and interdisciplinary disaster management. To advance knowledge on Capacity Building on the local level in the three pilot areas, extensive analysis of the given situations and corresponding administrative institutions was thoroughly carried out. It is indeed noteworthy to give evidence that remarkable progress has been accomplished in all above presented and actively initiated programmes and campaigns being implemented in regard to a sustainable capacity development. Indonesian institutions and governmental bodies progressively accepted and realized that a set of tailored Capacity Building programmes in correspondence to pure scientific and engineering approaches are meaningful instruments to foster the effectiveness of disaster mitigation policies and help shaping best-practice guidelines.

\subsection{Achievements and lessons learned}

It was mandatory to design and implement an adequate Capacity Building work package to be closely associated with the more technical and scientific focus of the main project. Envisaged goals have been accomplished in the academic and technical programmes, i.e. as of today a total of four PhD students successfully finished and defended their theses and another five candidates are about to submit their research work in the coming months as well as there are ample examples of successful joint workshops and symposia considered to expand abilities and expertise as well as to enhance intercultural exchange of scientists and technicians in the relevant organizations and institutions. Likewise, evident progress in effective disaster risk reduction has been achieved in the three pilot areas as Spahn et al. (2009) meticulously point out from experiences of local capacity development for tsunami early warning in Indonesia.

But apart from all technology and scientific knowledge based disaster preparation efforts stemming from the global scientific community, it was seen imperative that the national and local authorities in Indonesia ensure to realize that adequate disaster mitigation measures and preparedness schemes have to be taken into account in due time. This was part of the second work package within the Capacity Building programme. In this regard, it was determined that the acting disaster management government agencies on provincial (in Bahasa: Satkorlak) and local level (in Bahasa: Satlak) together with other important entities, i.e. NGOs, police, red crescent, etc. in the three pilot area are hardly integrated into the early warning system and moreover lack of capacities and networks relating with the national level. It was further exposed that risk maps, emergency or contingency plans did not exist and communication infrastructure in order to pass on warnings barely present. Yet, standard operational procedures (SOP) and responsibilities to react in case of a triggered warning were only insufficiently arranged, although local, but uncoordinated initiatives in disaster management programs have been in place without any connection to the national political level.

Yet, in addition to these findings, it also clear that without the society's understanding of the type and level of risk being exposed to, it is very difficult to advance and implement strategies for disaster risk reduction. It is quite often argued that the information and experience contained within the knowledge-practice-belief complex of communities and individuals is a most valuable, but often neglected area of information and understanding about past catastrophic events (King and Goff, 2010). This apparent mismatch is also made obvious by Shah (2006) as he addresses the importance of and issues related to the so-called Last-Mile. The term Last-Mile originates from the telecommunications industry, where it is defined as the most crucial link between available communication systems and tools and the use of that technology by an individual as the problem of the last mile. This concept states that, unless the last connection between the homeowner and the most sophisticated available technology is dysfunctional or even not established, all the available technology cannot be effective for the vast market of consumers. Thus, the problem of the Last-Mile continues 
to be a challenge in the communication industry to integrate and to some extent to take control of the processes on the last step to effectively address the recipient of the information. This Last-Mile concept is understood to develop in analogy effective disaster risk reduction schemes, i.e. as long as the people at risk due to any hazardous event remain, the early warning chain is ineffective, and, thus, adequate measures and strategies need to be established to close the final link that is to safe the lives of the people at risk.

In this regard Schiermeier (2009) also points out that five years after the Indian Ocean tsunami disaster, the most sophisticated early warning sensor network and technology is in place, but local administrative and thorough preparedness efforts on the Indonesian coastlines are still less advanced, i.e. to some extent even underdeveloped. This is only partly due to a lack of national coordination frameworks in terms of mainstreaming decentralized local preparedness initiatives, but largely due to missing links towards sustainable coastal zone management schemes on a broad local level for shaping long-term spatial planning development and enabling administrative guidelines. So, the question remains whether we are reaching the people who represent and live on the Last-Mile of the pathway to effective mitigation. What is needed according to Shaw (2006) is to create true integration of local stakeholders with their own traditional knowledge and experiences to effectively mitigate disaster risks. This evident conumdrum in coastal regions is not exclusively observed in the Indian Ocean region, but in other coastal regions worldwide, even in developed countries, yet, the demand and urgent need for adequate disaster risk reduction measures in the currently considered region of interest within GITEWS is (still) substantial.

True impacts will only be achieved when hazard issues are fully recognized and community-based actions are taken to improve the situation. This implies understanding the socioeconomic constraints in order to balance and interweave scientific and engineering insights and knowledge with non-scientific and non-technical matters, i.e. sources of indigenous knowledge, as the major role in implementing effective disaster risk reduction strategies. As pointed out earlier, any conceptual as well as operational design of a tsunami early warning system has to acknowledge and embed local structures, actors and capacities to create an integrated, so-called end-to-end system. Local authorities and tentatively affected people have to be made aware of, and, concurrently realize themselves the underlying risks in order to progress effective preparedness programs and strategies in the advent of natural hazards and in order to anticipate issued warning dossiers in a proper way and react adequately. Thus, it has been a primary objective to raise awareness and help developing appropriate preparedness strategies and mechanisms with the local authorities and scientist in a joint research and communication approach. From the beginning of all research and socialization activities in the three pilot regions, it was envisioned to integrate local stakeholders and authorities, nongovernmental organizations as well as to collaborate to a maximum degree with the scientists and researchers in addition to national experts into the tsunami study and evaluation process.

In addition, a sizeable series of consultation talks, symposia and workshops, and even conference, i.e. the Padang Consensus Process, together with the scientific community as well as national and local experts have been conducted (Schlurmann et al., 2010). Moreover, multi-national team efforts on bathymetrical and topographical surveys (Krabbenhoeft et al., 2010), sensor installations (Falck et al., 2010), socio-economic data collection campaigns and vulnerability assessments as those describe by Taubenboeck et al. (2009). All these Capacity Building measures could be taken as indicators or measures of success for an effective disaster risk reduction. Evacuation strategies and drills reported by Spahn et al. (2010) have been jointly carried out in order to maximize the Capacity Building impact and help enabling, yet, facilitating measuring, processing and interpreting geodata to advance knowledge to manage and operate a TEWS.

However, the latter objective has been only partly accomplished since it is essential to recognize that the local government of a district or city plays the most significant, yet, the crucial role when developing and initiating to execute research projects due to the fact the decentralization and democratization processes are still in progress. It was evident that districts (Kabupaten) and cities (Kota) permanently receive more and more competencies and responsibilities from the Indonesian government; especially in relation to disaster management and prevention policies. By constitution the Lord Mayor has the authority of making decisions in disastrous events, e.g. whether a city or coastal stretch is being evacuated or not due to any hazard or any other harmful occasion. So, the long-term and sustainable distribution of resources and civil protection of citizens is steered and maintained by the local authorities themselves. Decisions and processes are being taken and initiated by these institutions, respectively, and of course, responsibilities are also taken by them.

In fact, the stringent decentralization process within a country like Indonesia on the one end is beneficial for customized local disaster management schemes and likewise advantageous for an anticipated rapid response to tsunami warning dossiers in terms of evacuation. Therefore, the authors of this paper along with other colleagues and research as well as the local capacity building initiatives conducted and reported by Spahn et al. (2010), had to constantly elucidate, yet, interpret whether the local authorities and capacities are yet defined and how these (new) institutions are mandated to develop and operate an efficient combination of effective, interdisciplinary, integrated system in order to establish wide-ranging disaster management plans. It is acknowledged that the establishment 
of local disaster management schemes, relevant policymaking and its implications are today still in progress. It has to be made clear that these complex conditions in order to keep track of state and anticipate trends of local policymaking and governance structures in the related field of disaster management is demanding.

Nevertheless, first steps have been successfully accomplished towards effective local tsunami early warning system on the local level in the three pilot areas by jointly developing, discussing and finalizing an official set of tsunami hazard and risk maps and help commencing to generate and upgrade further preparedness measures and implications for adequate disaster management, although a long road is still ahead.

Yet, it turns out additionally after five years with the support from the German government that national efforts towards a sustainable Capacity Building programme under guidance of the State Ministry of Research and Technology of the Republic of Indonesia (RISTEK) are expanding in regard of self-initiating and self-coordinating the Capacity Building components for the Indonesian research institutions and coastal communities at risk within the framework of the full Indonesian tsunami early warning system, defined as InaTEWS.

\section{Re-iterated needs and demands in Capacity Building}

With regard to TEWS and through the initiative of GITEWS, evident needs have been identified and appropriate mechanisms for institutional, organizational and individual Capacity Building implemented. However, capacity building has to be considered as an everlasting process. New mechanisms and knowledge need to be institutionalized and further developed as well as facilitated and mainstreamed. Indonesia is aiming at establishing an integrated and decentralized disaster risk management system; Capacity Building in the context of TEWS may be seen as part of such an approach. Finally, in local pilot areas approved mechanisms to assure community preparedness and a functioning warning chain have been established. They need to disseminate and transfer results into other coastal regions at risk is mandatory. The demand for CB in TEWS in general and in disaster risk management in general remains unabated.

In order to maintain and update local disaster preparedness management schemes in one of the pilot regions, i.e. in city of Padang, it is most vital to take action in due time. According to various authors attention is drawn to the substantial tsunami hazard potential in the Indonesian densely-populated urban agglomeration with about 850000 inhabitants located on the western shore of Sumatra (Borrero et al., 2006; McCaffrey, 2007; McCloskey et al., 2007; Okal and Synolakis, 2008). In reference to these analyses, McCloskey et al. (2010) recently evaluate the 30 September 2009 earthquake and conclude from seismic records and subsequent calculations that even this particular and most recent quake in the region did not rupture the Sunda megathrust, so that it insignificantly relaxed the accumulated stress on the Mentawai segment and argue that the megathrust strain-energy budget remains substantially unchanged. As outlined beforehand, within the scope of ongoing research activities microscopic temporal and spatial tsunami inundation dynamics have been taken into account to set-up an official set of tsunami hazard and risk maps for the city of Padang. This objective has been achieved by interdisciplinary and multinational scientific and Capacity Building efforts by researchers and experts from Indonesia, USA, Japan and Germany in collaboration with local scientists and municipal authorities from Padang mid April 2010 by generating an Official Tsunami Hazard Map Padang which has been approved by the Lord Mayor of Padang in May 2010. This official tsunami hazard map is highly demanded for further planning and preparedness processes in order to proceed with the development of a community friendly evacuation plan by involving relevant stakeholders. The latter goal is work in progress. Demands for continuing and expanding efforts in Capacity Building remain large, also in the other two pilot regions, yet, in more or less all tsunami-prone coastal communities along the Indonesian Archipelago in total.

What is more is that the goals and objectives of this joint project are most significant for mainstreaming coastal zone management approaches and to transfer this particular methodological disaster risk reduction attempt towards other regions exposed to coastal hazards within Indonesia.

Local authorities from the three pilot regions are now being equipped with tools in disaster management and trained to develop counter measures and coping strategies so that they now could distribute their knowledge and planning experience to other coastal regions in future research or development cooperation projects.

\section{Conclusions}

From the very beginning it was envisioned that GITEWS in its final stage of development and integration into an operational and administrative framework was determined to achieve an integral architecture and overarching technical design of an end-to-end tsunami early warning system (TEWS). In order to achieve these ambitious goals, besides the development and complex integration of an operational sensor network and efficient decision support system on national and local level, a tailored set of capacity building measures has been conceived and implemented. This was meant and designed to meet requirements and urgent needs considering awareness raising campaigns, technical trainings and higher level education programs. These components have been integrated as complementary modules in order to ensure facilitating the system to be operated, maintained and 
improved, and that institutions and people at risk in coastal areas will respond adequately and timely in case of future tsunamis. Remarkable progress has been accomplished as well as programs and campaigns are being implemented in regard to a sustainable capacity development, despite the fact that also a number of important lessons have been learned. Five year after the Indian Ocean disaster, the most sophisticated early warning technology is in place, but local administrative and preparedness efforts on the Indonesian coastlines are still less advanced. This is only partly due to a lack of national coordination frameworks in terms of mainstreaming decentralized local preparedness initiatives, but largely due to missing links towards sustainable coastal zone management schemes on a broad local level. This evident conumdrum in coastal regions is not exclusively observed in the Indian Ocean region, but in other coastal regions worldwide, even in developed countries, yet, the demand and urgent need for adequate disaster risk reduction measures in the currently considered region of interest within GITEWS is substantial. Depicting that context and given the tragic loss of life and severe damages resulting from the December 2004 tsunami and recent series of severe earthquakes, the need for urgent mitigating action in the imperilled coastal regions of Sumatra and Java remains extremely high. Goals and objectives taken into account and the so far constructive steps achieved are most significant for mainstreaming scientific approaches and to transfer this methodological disaster risk reduction attempt towards other regions exposed to coastal hazards within Indonesia. Local authorities and researchers in tentative affected regions which are earmark the so-defined three pilot regions addressed in the GITEWS project, i.e. Padang, Bali and Cilacap, could now disseminate and apply their knowledge and planning experience to other coastal regions in the area to help facilitating and multiplying effective disaster management plans and strategies, also for multihazard purposes. These uncovered conditions allocate the framework for updated and to some extent re-iterated needs and demands in Capacity Building regarding coastal zone management in any future research or development cooperation project.

Acknowledgements. The GITEWS project (German Indonesian Tsunami Early Warning System) is carried out through a large group of scientists and engineers from different German research institutes under the leadership of the GFZ, German Research Centre for Geosciences. Funding is provided by the German Federal Ministry for Education and Research (BMBF), Grant 03TSU01. We would also like to thank our partners and colleagues from the national research institutions and agencies, i.e. National Agency for Meteorology, Climatology and Geophysics (BMKG - Badan Meteorologi Klimatologi dan Geofisika), National Coordinating Agency for Surveys and Mapping (Bakosurtanal Badan Koordinasi Survei dan Pemetaan Nasional), Agency for the Assessment \& Application of Technology (BPPT - Badan Pengkajian dan Penerapan Teknologi) and Indonesian Institute of
Science (LIPI - Lembaga Ilmu Pengetahuan Indonesia), under guidance and supervision of State Ministry for Research and Technology (RISTEK - Kementrian Negara Riset dan Teknologi) and all other relevant institutions for the support and outstanding assistance to help achieving an adequate and sustainable Capacity Building programme in Indonesia.

We would like to thank the reviewers and the editor for providing crucial suggestions to improve the quality of our manuscript. This is GITEWS publication no. 122.

Edited by: A. Rudloff

Reviewed by: G. Tetzlaff, C. E. Gregg, and another

anonymous referee

\section{References}

Bernard, E. N., Mofjeld, H. O., Titov, V., Synolakis, C. E. and Gonzalez, F. I.: Tsunami: scientific frontiers, mitigation, forecasting and policy implications, Philos. T. R. Soc. A, 364, 1989-2007, 2006.

Borrero, J. C., Sieh, K., Chlieh, M., and Synolakis, C. E.: Tsunami inundation modeling for Western Sumatra, Proceedings of the National Academy of Sciences of the United States of America, 103(52), 19673-19677, 2006.

Falck, C., Ramatschi, M., Subarya, C., Bartsch, M., Merx, A., Hoeberechts, J., and Schmidt, G.: Near real-time GPS applications for tsunami early warning systems, Nat. Hazards Earth Syst. Sci., 10, 181-189, doi:10.5194/nhess-10-181-2010, 2010.

Hoppe, M. and Mahadiko, H. S.: 30 minutes in Padang - lessons for tsunami early warning and preparedness from the earthquake on 30 September 2009. GTZ-GITEWS project publication (circulated via email), available at: www.gitews.org/tsunami-kit, 2010.

King, D. N. and Goff, J. R.: Benefitting from differences in knowledge, practice and belief: Ma-ori oral traditions and natural hazards science, Nat. Hazards Earth Syst. Sci., 10, 1927-1940, doi:10.5194/nhess-10-1927-2010, 2010.

Krabbenhoeft, A., Weinrebe, R. W., Kopp, H., Flueh, E. R., Ladage, S., Papenberg, C., Planert, L., and Djajadihardja, Y.: Bathymetry of the Indonesian Sunda margin-relating morphological features of the upper plate slopes to the location and extent of the seismogenic zone, Nat. Hazards Earth Syst. Sci., 10, 1899-1911, doi:10.5194/nhess-10-1899-2010, 2010.

Lauterjung, J., Münch, U., and Rudloff, A.: The challenge of installing a tsunami early warning system in the vicinity of the Sunda Arc, Indonesia, Nat. Hazards Earth Syst. Sci., 10, 641646, doi:10.5194/nhess-10-641-2010, 2010.

McCaffrey, R.: The next Great Earthquake, Science, 315, 16751676, 2007.

McCloskey, J., Antonioli, A., Piatanesi, A., Sieh, K., Steacy, S., Nalbant, S. S., Cocco, M., Giunchi, C., Huang, J. D., and Dunlop, P.: Near-field propagation of tsunamis from megathrust earthquakes, Geophys. Res. Lett., 34, L14316, doi:10.1029/2007GL030494, 2007.

McCloskey, J., Lange, D., Tilmann, F., Nalbant, S. S., Bell, A. F., Natawidjaja, D. H., and Rietbrock, A.: The September 2009 Padang earthquake, Nat. Geosci., 3(2), 70-71, 2010. 
Okal, E. A. and Synolakis, C. E.: Far-field tsunami hazard from mega-thrust earthquakes in the Indian Ocean, Geophys. J. Int., 172(3), 995-1015, 2008.

Rudloff, A., Lauterjung, J., Münch, U., and Tinti, S.: Preface "The GITEWS Project (German-Indonesian Tsunami Early Warning System)", Nat. Hazards Earth Syst. Sci., 9, 1381-1382, doi:10.5194/nhess-9-1381-2009, 2009.

Schiermeier, Q.: Tsunami Watch, Nature, 462, 968-969, doi:10.1038/462968a, 2009

Schlurmann, T., Kongko, W., Goseberg, N., Natawidjaja, D. H., and Sieh, K. E.: Near-field tsunami hazard map Padang, West Sumatra: Utilizing high resolution geospatial data and reasonable source scenarios, in: Proc. 32nd International Conference on Coastal Engineering (ICCE2010), American Society of Civil Engineers (ASCE), in press, 2010.

Shah, H. C.: The last mile: earthquake risk mitigation assistance in developing countries, Philos. T. R. Soc. A, 364, 2183-2189, 2006.
Sieh, K.: Sumatran megathrust earthquakes - from science to saving lives, Philos. T. R. Soc. A, 364, 1947-1963, 2006.

Spahn, H., Hoppe, M., Vidiarina, H. D., and Usdianto, B.: Experience from three years of local capacity development for tsunami early warning in Indonesia: challenges, lessons and the way ahead, Nat. Hazards Earth Syst. Sci., 10, 1411-1429, doi:10.5194/nhess-10-1411-2010, 2010.

Synolakis, C. E. and Bernard, E.: Tsunami science before and beyond Boxing Day 2004, Philos. T. R. Soc. A, 364, 2231-2265, 2006.

Taubenböck, H., Goseberg, N., Setiadi, N., Lämmel, G., Moder, F., Oczipka, M., Klüpfel, H., Wahl, R., Schlurmann, T., Strunz, G., Birkmann, J., Nagel, K., Siegert, F., Lehmann, F., Dech, S., Gress, A., and Klein, R.: "Last-Mile" preparation for a potential disaster - Interdisciplinary approach towards tsunami early warning and an evacuation information system for the coastal city of Padang, Indonesia, Nat. Hazards Earth Syst. Sci., 9, 1509-1528, doi:10.5194/nhess-9-1509-2009, 2009. 